\title{
Efficiency of test report delivery to the requesting physician in an outpatient setting: an observational study
}

\author{
Ana-Maria Simundic*, Nora Nikolac, Marijana \\ Miler, Andrea Cipak and Elizabeta Topic \\ University Department of Chemistry, University \\ Hospital "Sestre milosrdnice", Zagreb, Croatia
}

\begin{abstract}
Background: Clinical laboratories accredited according to ISO 15189 quality standards are obliged to implement and continuously monitor quality indicators for evaluation of the laboratory's contribution to patient care. Reporting laboratory results to the requesting physician is one important phase of the clinical laboratory testing process. Failure to report results may indicate the ineffectiveness of the laboratory service. We aimed to analyze the proportion and type of laboratory reports for outpatients that were not delivered to the requesting physician.

Methods: This retrospective observational study was conducted during an 11-month period from January to December 2007 at our outpatient biochemistry laboratory unit. Data on demographic characteristics, request types and laboratory findings for all uncollected reports were retrieved from the laboratory information system and compared with one random 2-week representative period.
\end{abstract}

Results: During the study period our laboratory issued 22,445 patient reports with more than 150,000 biochemistry analyses. Of these, 464 (2.1\%) were uncollected laboratory reports. When compared to the representative period, patients who never collected their laboratory reports were younger $(p<0.001)$ or suffering from some chronic disease. Routine biochemistry tests were the most prevalent (>50\%). The majority of routine biochemistry tests were almost equally represented during the study and representative period, while molecular diagnostic tests were several times more frequently uncollected $(p<0.001)$. Reports with electrolytes, metabolites and glucose were the least likely to be uncollected $(p<0.001)$. The total cost for those tests was $30 \%$ of the average monthly laboratory budget.

Conclusions: A significant amount of the laboratory budget is wasted for tests that never reach the requesting physician. Such misutilization of the laboratory reveals the substantial lack of medical necessity for test requests. Further studies are needed to explore the possible efficiency of the various inter-

*Corresponding author: Assist. Prof. Ana-Maria Simundic, PhD, University Department of Chemistry, Department of Molecular Diagnostics, University Hospital "Sestre milosrdnice", 10000 Zagreb, Croatia

E-mail: am.simundic@gmail.com

Received March 21, 2009; accepted June 17, 2009 ventions in reducing the volume of unnecessary and erroneous testing.

Clin Chem Lab Med 2009;47:1063-6.

Keywords: accreditation; erroneous test; healthy care efficiency; laboratory report delivery; outpatient setting.

\section{Introduction}

Clinical laboratories accredited according to ISO 15189 quality standard are obliged to implement and continuously monitor quality indicators for evaluation of the laboratory's contribution to patient care. Quality indicators can either be measures of processes, outcomes or contribution of the laboratory to patient care $(1-3)$. It is crucial that quality indicators address all three key processes in the laboratory: preanalytical, analytical and postanalytical $(1,4)$. Reporting laboratory results to the requesting physician is one important phase of the clinical laboratory testing process. Failure to notify the physician of test results may indicate the ineffectiveness of the laboratory service. Results never reported to the physician affect the quality of patient care and unnecessarily waste financial health resources. Computerized automated communication may significantly improve the effectiveness and timeliness of laboratory report notification in large clinical laboratories (5). However, it does not solve the issue of unjustified or unnecessary requests. Furthermore, the efficiency of timely delivery of test reports to the requesting physician in an outpatient setting is questionable. We analyzed the proportion and type of laboratory reports for outpatients that were never delivered to the requesting physician. To the best of our knowledge, such a survey has not been performed or reported in the literature.

\section{Materials and methods}

\section{Setting}

This retrospective observational study was conducted during an 11-month period from January to December 2007 at an outpatient biochemistry laboratory unit of the University Department of Chemistry at the University hospital "Sestre milosrdnice", in Zagreb, Croatia. Our hospital is a 900-bed tertiary care University hospital. The laboratory is accredited according to ISO 15189 standard and performs up to three million tests per year with a following test panel: routine general biochemistry, urine analysis, protein analysis, autoimmune disease testing, neurobiochemistry, toxicology, molecular diagnostics, hematology and coagulation. On 
average, there are 80 outpatients per day in our laboratory. Upon completion, a hard copy outpatient test report is collected by the patient. For the majority of test parameters, the turn-around time (TAT) is 1 working day. For autoimmune disease testing and molecular diagnostics, the TAT may be up to 4 weeks. Since the hematology and coagulation outpatient unit is not located in our central laboratory, we excluded their reports from this analysis.

\section{Data retrieval}

We analyzed data on demographic characteristics, request types and laboratory findings for all uncollected reports in the study period. Laboratory reports were considered uncollected if not collected within 3 months after being issued. In order to compare parameters of the uncollected reports with what is considered average, we chose one random 2-week representative period for comparison. The following demographic data were collected: patient age, gender, diagnosis, residence (people living in Zagreb vs. those living outside Zagreb), cost for requested analyses as refunded by the health insurance company and the amount co-payment paid by the patient. Depending on the type of insurance, patients may have $0 \%-100 \%$ coverage from the insurer. Laboratory findings were categorized as (i) within the reference interval, (ii) borderline, and (iii) outside the reference interval. Borderline results were considered as those exceeding the lower/upper reference value by $<5 \%$. Data needed for analysis were retrieved from our laboratory information system.

\section{Statistical analysis}

Distribution of each continuous quantitative variable was assessed for normality using the Kolmogorov-Smirnov test. Descriptive categorical data were presented as numbers (counts) and percentages. Continuous quantitative variables showed deviation from normality and were, therefore, presented as medians and interquartile ranges. Differences between observed proportions were tested with the $\chi^{2}$ and z-test. Differences between continuous variables were tested with the non-parametric Mann-Whitney test. The level of significance was set at 0.05 . Statistical analysis was performed using MedCalc ${ }^{\circledR}$ statistical software (MedCalc 10.1.3.1, Frank Schoonjans, Mariakerke, Belgium).

\section{Results}

There were a total of 22,445 patient reports with more than 150,000 biochemistry analyses tested during this 11 -month survey. Of this total, we registered 464 (2.1\%) uncollected laboratory reports (1569 analyses). The total cost for analyses for the reports that were never collected was $30 \%$ of the average monthly laboratory budget. There were 1122 reports $(11,834$ analyses) during the representative period. Patient demographic data and cost of the analyses for uncollected reports and the representative period are shown in Table 1.

When compared to the representative period, patients who never collected their laboratory reports were younger $(p<0.001)$. The average total cost for uncollected test reports was $40 \%$ higher $(p=0.001)$. Of those who never collected their reports, more patients lived outside Zagreb.

There were $36 \%$ of patients in the age group of 19-50 years who did not collect their reports, as opposed to $25 \%$ in the representative period. Older patients ( $>70$ years) were more likely to collect their reports $(p=0.009)$, as shown in Table 2 .

For those who did not collect their reports, the majority of laboratory findings were within the reference interval, while only one-third of the patient findings were borderline or outside the reference interval (Table 3).

In order to explore whether patients with certain diagnoses collect their reports, we tested for possible differences between proportions of diagnoses during the two study periods. Diagnoses were equally represented within the two study groups (data not presented). Patients who did not collect their laboratory reports during both study periods were more likely to be individuals suffering from some chronic disease. Almost $60 \%$ of these were patients with diabetes mellitus, thyroid disease, iron deficiency anemia or osteoporosis. The only modest difference observed was in the proportion of thyroid disease among studied periods. There were $9.0 \%$ and $4.8 \%$ of patients with chronic thyroid disease among the uncollected reports group and representative period, respectively $(\mathrm{p}=0.050)$.

To assess whether reports with certain analyses are collected more often, we tested the possible difference between types of analyses during the two study periods. Routine biochemistry tests were the most prevalent $(>50 \%)$. The majority of routine biochemistry tests were almost equally represented during the study and representative periods. However, some more expensive analyses such as molecular diagnostic tests were several times more frequently uncollected $(p<0.001)$. Reports with electrolytes, metabolites and glucose were the least likely to be uncollected $(p<0.001)$ (Table 4).

\section{Discussion}

There is a growing need to introduce measurable and evidence based indicators of laboratory efficiency and

Table 1 Patient demographic data and total cost for uncollected reports and the 2-week representative period.

\begin{tabular}{|c|c|c|c|}
\hline Parameters & $\begin{array}{l}\text { Representative period } \\
n=1122\end{array}$ & $\begin{array}{l}\text { Uncollected reports } \\
n=464\end{array}$ & p-Value \\
\hline Male gender, n (\%) & $392(34.9)$ & $174(37.5)$ & $0.362^{a}$ \\
\hline Age, years & $58(43-69)$ & $53(35-66)$ & $0.001^{\mathrm{b}}$ \\
\hline Living in Zagreb, n (\%) & $758(67.6)$ & $299(64.4)$ & $0.012^{a}$ \\
\hline Total cost, $€$ & $17.22(7.13-37.77)$ & $23.99(8.42-50.92)$ & $0.001^{\mathrm{b}}$ \\
\hline Patient co-pay, $€$ & $0.49(0-3.10)$ & $0(0-3.63)$ & $0.102^{\mathrm{b}}$ \\
\hline
\end{tabular}

${ }^{\mathrm{a}} \chi^{2}$-test; ${ }^{\mathrm{b}}$ Mann-Whitney test. 
Table 2 Patient age distribution for uncollected reports $(n=440)$ and representative period $(n=1112)$.

\begin{tabular}{llcr}
\hline Age, years & $\begin{array}{l}\text { Representative } \\
\text { period, } \mathrm{n}(\%)\end{array}$ & $\begin{array}{l}\text { Uncollected } \\
\text { reports, } \mathrm{n}(\%)\end{array}$ & $\mathrm{p}$-Value \\
\hline$\leq 18$ & $108(9.7)$ & $37(8.4)$ & 0.486 \\
$19-30$ & $69(6.2)$ & $52(11.8)$ & $<0.001$ \\
$31-50$ & $212(19.1)$ & $106(24.1)$ & 0.032 \\
$51-70$ & $498(44.8)$ & $182(41.4)$ & 0.243 \\
$>70$ & $225(20.2)$ & $63(14.3)$ & 0.009 \\
\hline
\end{tabular}

a Mann-Whitney test.

Table 3 Laboratory findings for patients who never collected their reports $(n=464)$.

\begin{tabular}{lc}
\hline Laboratory findings & $\mathrm{n}(\%)$ \\
\hline Borderline & $28(6.0)$ \\
Within reference interval & $305(65.7)$ \\
Outside reference interval & $131(28.2)$ \\
\hline
\end{tabular}

its contribution to clinical effectiveness into every segment of the health care system (6-8). Erroneous and unnecessary test requests surely increase health care expenditure and reduce the quality of patient care. Quality of patient care is endangered by both unnecessary phlebotomy which might lead to iatrogenic anemia (9), and by failing to provide adequate care to the patient.

Our aim was to analyze the volume and the total cost of laboratory reports never seen by the requesting physician. The key finding of this study is that a significant amount of the laboratory budget is wasted for tests that never reach the requesting physician. In our opinion, such misutilization of the laboratory surely demonstrates the substantial lack of medical necessity for test requests.

Quite interestingly, middle aged patients whose biochemical parameters were within the reference interval and who were suffering from some chronic disease were more likely not to collect their reports when compared to children, teenagers or older individuals. The possible explanation could be that the requesting physician ordered unnecessary tests for those patients. Inappropriate use of the laboratory has been widely documented in clinical practice (10-12).

Although the majority of uncollected reports were those for routine biochemistry tests, it is quite a paradox that reports for highly specialized and more expensive tests were more likely to be uncollected. For example, molecular diagnostic panels for inherited thrombophilia risk screening, which accounted for only $3 \%$ of all uncollected reports, had the highest probability to be uncollected. The possible explanation for this might be that these tests have longer TATs. Thus, patients could easily forget that there are some reports missing after waiting for 3-4 weeks.

Patients who suffer from some chronic disease and are referred from their primary care physician for some additional or regular periodic diagnostic workup might not be highly motivated to collect their laboratory findings. It is possible that they cannot foresee the direct benefit of the testing. On the other hand, patients having an acute condition and requiring some action from their physician are probably more motivated to collect their reports.

One very interesting question is why does not a requesting physician request the results himself or stimulate his patient to get them? Specific proteins, vitamins, autoimmune disease markers and molecular diagnostic tests are certainly not routine but rather expensive laboratory tests. The requesting physician is supposed to have a sound knowledge that such tests exist, but also understand the rationale of the test itself. In that respect, it is difficult to believe that physicians are not interested in test results. The reason why the physician is not stimulating the patient to collect the test report is yet to be explored.

Table 4 Difference between uncollected and collected test results relative to the test panel groups during the studied period of 11 months.

\begin{tabular}{lcccc}
\hline Test panel & $\begin{array}{l}\text { Representative period, } \\
\text { (total number of } \\
\text { analyses }=11,834), \mathrm{n}(\%)\end{array}$ & $\begin{array}{l}\text { Uncollected reports, } \\
\text { (total number of } \\
\text { analyses=1569), } \mathrm{n}(\%)\end{array}$ & $\mathrm{p}$-Value $\mathrm{a}^{\mathrm{a}}$ & $\mathrm{OR}(95 \% \mathrm{Cl})$ \\
\hline Molecular diagnostics & $48(0.41)$ & $50(3.19)$ & $<0.001$ & $7.86(5.26-11.72)$ \\
Toxicology & $18(0.15)$ & $14(0.89)$ & $<0.001$ & $5.87(2.91-11.82)$ \\
Vitamins & $42(0.35)$ & $20(1.27)$ & $<0.001$ & $3.59(2.10-6.13)$ \\
Immunology & $243(2.05)$ & $107(6.82)$ & $<0.001$ & $3.32(2.63-4.19)$ \\
Autoimmune disease testing & $408(3.45)$ & $121(7.71)$ & $<0.001$ & $2.24(1.82-2.76)$ \\
Occult blood test & $26(0.22)$ & $7(0.45)$ & 0.097 & $2.03(0.88-4.69)$ \\
Proteins & $793(6.70)$ & $146(9.31)$ & $<0.001$ & $1.39(1.16-1.67)$ \\
Therapeutic drug monitoring & $76(0.64)$ & $11(0.70)$ & 0.787 & $1.09(0.58-2.06)$ \\
Trace elements & $909(7.68)$ & $123(7.84)$ & 0.838 & $1.02(0.84-1.24)$ \\
Lipids and lipoproteins & $1377(11.64)$ & $191(12.17)$ & 0.581 & $1.05(0.89-1.23)$ \\
Enzymes & $2095(17.70)$ & $266(16.95)$ & 0.539 & $0.96(0.83-1.10)$ \\
Electrophoresis & $238(2.01)$ & $29(1.85)$ & 0.671 & $0.92(0.62-1.36)$ \\
Bone markers & $198(1.67)$ & $25(1.53)$ & 0.681 & $0.91(0.60-1.40)$ \\
Urinalysis & $218(1.84)$ & $193(12.30)$ & 0.496 & $0.87(0.57-1.31)$ \\
Metabolites & $2039(17.23)$ & $190(12.11)$ & $<0.001$ & $0.71(0.61-0.84)$ \\
Electrolytes & $2176(18.39)$ & $51(3.25)$ & $<0.001$ & $0.66(0.56-0.77)$ \\
Glucose metabolism & $850(7.18)$ & $1(0.06)$ & $<0.001$ & $0.45(0.34-0.60)$ \\
Blood gas testing & $80(0.68)$ & & 0.019 & $0.09(0.01-0.68)$ \\
\hline
\end{tabular}

a-test. OR, odds ratio; $\mathrm{Cl}$, confidence interval. 
Many attempts have been made with the aim of improving the appropriateness of test requesting behavior, as well as reducing the testing volume (13-15). Continuous education of medical doctors has been demonstrated as an effective means for decreasing redundant tests ordering in the hospital setting (16) as well as by practicing community physicians (17).

The authors of this work agree that educational intervention might be, to some extent, effective in reducing the volume of unnecessary testing. This hypothesis should, however, be properly tested in the appropriate clinical setting.

The other issue is the delivery mode for test reports. In our country, it is the responsibility of the patient to collect his or her report. If the test was not needed in the first place, or the time interval needed to issue the report is too long, the laboratory report is more likely not to be collected. Implementing electronic delivery systems of laboratory reports to the requesting physician might be a way to improve the effectiveness of patient care. There is strong evidence on the effectiveness of systems for electronic request and delivery of test reports in terms of improving health care in primary care practices (18).

Based on our results, we conclude that a significant amount of the laboratory budget is wasted for tests that never reach the requesting primary care physician. Further studies are needed to explore the possible efficiency of the various interventions in reducing the volume of unnecessary and erroneous testing.

\section{Conflict of interest statement}

The authors declare no conflicting interests.

\section{Acknowledgements}

This work is supported by the Ministry of Science, Education and Sports, Republic of Croatia. Project number: 1341340227-0200.

\section{References}

1. Ricós C, García-Victoria M, de la Fuente B. Quality indicators and specifications for the extra-analytical phases in clinical laboratory management. Clin Chem Lab Med 2004;42:578-82.

2. Kirchner MJ, Funes VA, Adzet CB, Clar MV, Escuer MI, Girona JM, et al. Quality indicators and specifications for key processes in clinical laboratories: a preliminary experience. Clin Chem Lab Med 2007;45:672-7.

3. Simundic AM, Topic E. Quality indicators. Biochemia Medica 2008;18:311-9.

4. Plebani M. Laboratory errors: how to improve pre- and post-analytical phases? Biochemia Medica 2007;17:5-9.

5. Piva E, Sciacovelli L, Zaninotto M, Laposata M, Plebani M. Evaluation of effectiveness of a computerized notification system for reporting critical values. Am J Clin Pathol 2009;131:432-41.

6. Waise A, Plebani M. Which surrogate marker can be used to assess the effectiveness of the laboratory and its contribution to clinical outcome? Ann Clin Biochem 2001;38:589-95.

7. Lippi G, Fostini R, Guidi GC. Quality improvement in laboratory medicine: extra-analytical issues. Clin Lab Med 2008;28:285-94.

8. Challand GS, Li P. The assessment of interpretation of test results in laboratory medicine. Biochemia Medica 2009;19:146-53.

9. DeBellis RJ. Anemia in critical care patients: incidence, etiology, impact, management, and use of treatment guidelines and protocols. Am J Health Syst Pharm 2007; 64:S14-21.

10. Salvagno GL, Lippi G, Targher G, Montagnana M, Guidi GC. Monitoring glycaemic control: is there evidence for appropriate use of routine measurement of glycated haemoglobin? Clin Chem Lab Med 2007;45:1065-7.

11. Attali M, Barel $Y$, Somin M, Beilinson N, Shankman M, Ackerman $A$, et al. A cost-effective method for reducing the volume of laboratory tests in a university-associated teaching hospital. Mt Sinai J Med 2006;73:787-94.

12. Wang TJ, Mort EA, Nordberg $P$, Chang $Y$, Cadigan ME, Mylott $L$, et al. A utilization management intervention to reduce unnecessary testing in the coronary care unit. Arch Intern Med 2002;162:1885-90.

13. Calderon-Margalit R, Mor-Yosef S, Mayer M, Adler B, Shapira SC. An administrative intervention to improve the utilization of laboratory tests within a university hospital. Int J Qual Health Care 2005;17:243-8.

14. Verstappen WH, van der Weijden T, Dubois WI, Smeele I, Hermsen J, Tan FE, et al. Improving test ordering in primary care: the added value of a small-group quality improvement strategy compared with classic feedback only. Ann Fam Med 2004;2:569-75.

15. Bates DW, Kuperman GJ, Jha A, Teich JM, Orav EJ, Ma'luf N, et al. Does the computerized display of charges affect inpatient ancillary test utilization? Arch Intern Med 1997;157:2501-8

16. Miyakis S, Karamanof G, Liontos M, Mountokalakis TD. Factors contributing to inappropriate ordering of tests in an academic medical department and the effect of an educational feedback strategy. Postgrad Med J 2006;82: 823-9.

17. Bunting PS, Van Walraven C. Effect of a controlled feedback intervention on laboratory test ordering by community physicians. Clin Chem 2004;50:321-6.

18. Kern LM, Barrón Y, Blair AJ 3rd, Salkowe J, Chambers D, Callahan MA, et al. Electronic result viewing and quality of care in small group practices. J Gen Intern Med 2008;23:405-10. 